\title{
UJI WEB SERVER
}

INDRI DEVITA PRATIWI dan NURAINI

JURUSAN TEKNIK INFORMATIKA, UNIVERSITAS LANCANG KUNING

EMAIL : indridevitap@gmail.com \& ainiiinur18@gmail.com

\begin{abstract}
ABSTRAK
Perkembangan Internet yang semakin hari semakin meningkat baik teknologi dan penggunaannya, membawa banyak dampak baik positif maupun negatif. Tentunya untuk yang bersifat positif. Saat ini website merupakan salah satu layanan informasi yang banyak diakses oleh pengguna internet di dunia. Sebagai salah satu layanan informasi maka perlu dibangun website yang mampu menangani permintaan (request) dari banyak pengguna dengan baik. Sifat heterogen dari perangkat lunak dan penyebaran yang terdistribusi memperkenalkan kompleksitas di dalam perangkt lunak yang harus ditangani selama pengujian. Di Universitas Lancang Kuning memiliki website resmi https://unilak.ac.id/, ketika suatu website dapat diakses
\end{abstract}

\section{PENDAHULUAN}

Web atau istilah lengkapnya web site atau juga sering disebut home page adalah suatu halaman yang berisi sejumlah informasi yang dapat diakses dan dibaca melalui oleh seluruh pengguna internet meskipun hanya secara terbatas, maka server website pun telah terhubung ke Internet. Oleh sebab itu administrator web dituntut untuk lebih berhati-hati, karena sangat memungkinkan bahwa layanan website tersebut akan disalah gunakan oleh hacker. Hacker sering melakukan aksinya dengan memanfaatkan dan menjadikan layanan website sebagai perantara untuk mendapatkan akses menuju server melalui celah keamanan yang terdapat pada layanan website.("Nurliana Nasution dan Mhd.Arief Hasan").

Kata Kunci : Pengujian Server Web dan Hosting Server.

sistem jaringan dengan menggunakan program browser. Informasi yang dapat ditampilkan lewat web dapat berupa tulisan, gambar, dan bahkan audio visual pun bisa ditampilkan.

Untuk memasang web agar bisa di 
baca oleh orang lain dari komputer lain di dalam sistem jaringan, baik jaringan lokal (LAN) maupun jaringan berbasis luas (WAN dan Internet) maka memerlukan program yang dapat memberikan layanan web atau web server. Web server ada yang dibuat secara terpadu dengan program sistem operasi dan secara terpisah. Program web server ada banyak jenisnya, seperti apache, abbys, xitami dan IIS (Internet Information Service). Untuk program web server IIS (Internet Information Service) sudah menjadi satu paket di dalam sistem operasi windows 2000 server.

Sehingga dapat dikatakan bahwa web server adalah software server yang menjadi tulang belakang dari World Wide Web (WWW). Web server menunggu permintaan dari client yang menggunakan browser seperti netscape navigator, Internet Explorer, mozilla firefox, dan program browser lainnya. Jika ada permintaan dari browser, maka web server akan memproses permintaan itu dan kemudian memberikan hasil prosesnya berupa data yang diinginkan kembali ke browser. Web server, untuk berkomunikasi dengan clientnya (web browser) mempunyai protokol sendiri yaitu HTTP (HyperText Transfer Protocol). Dengan protokol ini, komunikasi antar web server dengan clientnya (browser) dapat saling dimengerti dan lebih mudah.("Evy Nurmiati").

\section{DASAR TEORI}

Web server adalah software yang menjadi tulang belakang dari world wide web (www) yang pertama kali tercipta sekitar tahun 1980an. Web server menunggu permintaan dari client yang menggunakan browser seperti Netscape Navigator, Internet Explorer, Mozilla Firefox, dan program browser lainnya. Jika ada permintaan dari browser, maka web server akan memproses permintaan itu kemudian memberikan hasil prosesnya berupa data yang diinginkan kembali ke browser.

Data ini mempunyai format yang standar, disebut dengan format SGML (Standar General Markup Language). Data yang berupa format ini kemudian akan ditampilkan oleh browser sesuai dengan kemampuan browser tersebut. Contohnya, bila data yang dikirim berupa gambar, browser yang hanya mampu menampilkan teks (misalnya lynx) 
tidak akan mampu menampilkan gambar tersebut, dan jika ada akan menampilkan alternatifnya saja.

Web server, untuk berkomunikasi dengan client-nya (web browser) mempunyai protokol sendiri, yaitu HTTP (hypertext transfer protocol). Dengan protokol ini, komunikasi antar web server dengan client-nya dapat saling dimengerti dan lebih mudah. Seperti telah dijelaskan diatas, format data pada world wide web adalah SGML. Tapi para pengguna internet saat ini lebih banyak menggunakan format HTML (hypertext markup language) karena penggunaannya lebih sederhana dan mudah dipelajari.

a. Keamanan Komputer

Tujuan dari keamanan komputer untuk melindungi informasi komputer yang berada di dalamnya (Harjowinoto, Noertjahyana, \& Andjarwirawan, 2016). Keamanan komputer sendiri meliputi beberapa aspek seperti yang tercantum di modul Ethical Hacking and Countermeasures, antara lain : a. Privacy, adalah sesuatu yang bersifat rahasia (private) dimana ada pembatasan hak akses oleh orang tertentu saja.
b.Confidentiality, adalah pemberian data ke pihak lain tetapi tetap dijaga penyebarannya.

c. Integrity, adalah informasi yang tidak boleh diubah kecuali oleh pemilik informasi. d.Authentication, adalah verifikasi pengguna melalui tampilan login dengan menggunakan nama user dan kata sandinya, jika cocok diterima dan sebaliknya.

e.Availability, adalah kesediaan data saat dibutuhkan. Adapun beberapa langkah untuk mengamankan komputer seperti yang terlampir dalam modul Ethical Hacking and Countermeasures, yakni:

a. Aset, Perlindungan aset merupakan hal yg penting dan merupakan langkah awal dari berbagai implementasi keamanan komputer.

b. Analisa Resiko, identifikasi terhadap resiko yang mungkin terjadi, seperti sebuah event yang berpotensial untuk mengakibatkan kerugian terhadap sistem.

c. Keamanan jaringan, semua perangkat yang tersambung

pada 
jaringan

perlu

diperhatikan

keamanannya.

d.Tools,tool yang

digunakan pada PC

memiliki peran penting

dalam hal keamanan

karena tool yang

digunakan harus benar benar aman.

e.Prioritas, perlindungan

PC secara menyeluruh.

b. Keamanan Server

Tidak ada server komputer yang benar-benar aman. Sebuah server membutuhkan sistem jaringan untuk berkomunikasi. Setiap komunikasi dapat jatuh ke tangan orang lain dan dapat disalahgunakan.

Sistem keamanan membantu mengamankan server dan jaringannya tanpa menghalangi penggunaannya dan menempatkan antisipasi ketika jaringan berhasil ditembus. Selain itu, pastikan bahwa user dalam jaringan memiliki pengetahuan yang cukup mengenai keamanan dan pastikan bahwa mereka menerima dan memahami rencana keamanan yang dibuat. Jika tidak memahami hal tersebut, maka harus menciptakan suatu lubang (hole) keamanan pada jaringan yang ada (Harjowinoto, Noertjahyana,\&Andjarwirawa, 2016). Keamanan komputer, dalam hal ini server meliputi beberapa aspek antara lain :

a.Confidentiality.

Confidentiality attack adalah pencegahan dalam menjaga informasi dari orang yang tidak berhak dan tidak berkepentingan untuk mengakses.

b. Integrity

Integrity adalah upaya pencegahan terhadap informasi yang tidak boleh diubah dan dihapus tanpa seijin pemilik informasi.

c.Availability

Availability adalah upaya pencegahan ditahannya informasi atau sumber daya terkait oleh mereka yang tidak berhak dimana berhubungan dengan ketersediaan informasi ketika dibutuhkan.

d.Non-repudiation.

Non-repudiation merupakan hal yang yang bersangkutan dengan pengirim yang melakukan transaksi dan penerima. Aspek ini menjaga agar seseorang tidak dapat menyangkal telah melakukan sebuah transaksi.

e.Authentication 
Authentication adalah suatu langkah untuk menentukan atau mengonfirmasi bahwa pengirim suatu informasi yang ada dapat diidentifikasi dengan benar dan ada jaminan bahwa identitas yang didapat tidak palsu. Melakukan autentikasi terhadap sebuah objek adalah melakukan konfirmasi terhadap kebenarannya, sedangkan melakukan autentikasi terhadap seseorang biasanya adalah untuk memverifikasi identitasnya, dengan kata lain informasi tersebut benarbenar dari orang yang dikehendaki.

c. Hacker

Pada dasarnya ada tiga jenis hacker tergantung pada domain dari pekerjaan seseorang. Adapun beberapa hacker itu antara lain :

- White hat hacker, merupakan orang yang menulusuri atau memecah sistem keamanan komputer untuk tujuan yang tidak berbahaya. Tujuan-tujuan ini berkisar pada pengujian sistem keamanan untuk menemukan celah besar dalam jaringan. Orangorang seperti biasanya mengikuti cara yang sah dan bekerja dalam wilayah hukum cyber.

- Black hat hacker, umumnya menumbangkan keamanan komputer tanpa otorisasi dengan bantuan berbagai virus dan hacking tools lainnya. Hacker ini menggunakan teknologi untuk penipuan vandalisme, kartu kredit, atau pencurian identitas.

- Grey hat hacker, merupakan bagian pertengahan jalan antara black hat hacker dan white hat hacke.

d. Keamanan Jaringan

Satu hal yang perlu diingat bahwa tidak ada jaringan yang anti sadap atau tidak ada jaringan komputer yang benarbenar aman (Angir, Noertjahyana, \& Andjarwirawan, 2015). Sifat dari jaringan adalah melakukan sebuah komunikasi. Setiap komunikasi dapat jatuh ke tangan orang lain dan dapat disalahgunakan.

Sistem keamanan membantu mengamankan jaringan tanpa menghalangi penggunaannya dan menempatkan antisipasi ketika jaringan berhasil ditembus Keamanan jaringan ini dapat bertujuan untuk agar 
pemilik sistem informasi dapat menjaga sistem informasinya tidak ditembus atau disusupi oleh orang lain yang pada akhirnya dapat merusak sistem. Adapun tipe dari penyusup ini dapat berupa: the curious, the malicious, the high-profile intruder, dan the competition. Jenis-jenis segi keamanan jaringan yang ada antara lain : confidentiality, integrity, availability, non-repudiation, authentication, dan accountability. Digital Signature adalah salah satu teknologi yang digunakan untuk meningkatkan keamanan jaringan dan berfungsi untuk memastikan bahwa tidak ada data yang berubah. Cara kerja digital signature dilihat telah memenuhi salah satu syarat keamanan jaringan, yaitu Nonrepudiation.

- Perangkat Lunak (Software) Web Server

Web server

memiliki program pendukung yang kemudian digunakan dalam teknologi web, adapun jenis perangkat lunak

web server dapat

dibagi menjadi

beberapa bagian,

yaitu :

1) Konvensional

HTML merupakan singkatan dari HyperText Markup Language. HTML adalah dokumen text yang bisa dibaca untuk dipublikasikan di World Wide Web (WWW), dan semua nama file dokumen HTML mempunyai ekstensi html atau htm. Dalam sebuah dokumen HTML anda akan melihat tags. Tags adalah penempatan atau nilai format teks yang memerintahkan browser untuk menampilkan sebuah dokumen html.

ASP atau bisa juga dikenal dengan Active Server Pages. Server scripting yang memungkinkan untuk membuat web dinamis dan interaktif. Sejatinya halaman ASP adalah sekumpulan script yang dieksekusi, diproses di web server, dan kemudian hasil dari eksekusi tersebut baik berupa halaman HTML, maupun format data lain yang di inginkan (XML, teks, dII), dikirimkan ke web browser. (PC Mild edisi 24/03/2007)

PHP adalah salah satu bahasa pemrograman web yang open 
source, kode PHP dapat digabungkan dengan kode HTML untuk membentuk suatu halaman web yang dinamis, dalam konsep web, jika suatu web browser mengakses file dengan kode HTML murni maka web server akan mengirimkan file terakses secara utuh tanpa ada proses terlebih dahulu terhadap kode-kode yang digunakan dalam file tersebut, berbeda dengan file PHP, web server akan mengirimkan file PHP tersebut ke suatu program kompiler (dalam hal ini adalah PHP kompiler) untuk segera diproses, PHP compiler tersebut akan mengirimkan hasil prosesnya ke web server untuk segera dikirimkan kembali ke program pengakses. Hal ini akan memudahkan pembuat website untuk mengembangkan website dinamis, dalam hal ini website yang dapat merespon apa yang diminta oleh masing-masing program pengakses.

Java adalah sebuah bahasa pemrograman dan juga sebuah platform. Sebagai sebuah bahasa pemrograman tingkat tinggi, Java adalah sebuah bahasa berorientasi objek (object oriented programming). Jika pernah memprogram dengan bahasa pemrograman
OOP, seperti C++ atau Smalltalk, mungkin ingat betapa menyenangkannya memprogram dengan konteks objek. Program ini merancang beberapa objek satu demi satu dengan mendefinisikan berbagai property yang dimiliki object tersebut dan pekerjaan (task) yang dapat ditangani oleh objek tersebut. Kemudian merangkai semua objek tersebut dengan mendefinisikan relasi antar objek tersebut seperti halnya membangun sebuah mobil dari komponenkomponennya. Satu lagi yang ditawarkan oleh Java, dan tampaknya sampai saat ini baru Java yang memiliki ini, adalah sifat portabilitas dan independensi terhadap arsitektur dari programprogram yang ditulis dengan $100 \%$ Java. Yang dimaksud dengan portabilitas dan independensi terhadap arsitektur adalah : sebuah program yang dibuat dengan Java akan dapat dijalankan pada semua mesin atau komputer yang mempunyai Java Virtual Machine.

2) Micro Web Server

Cisco micro web server merupakan suatu web server 
yang sangat mudah untuk diinstal, memiliki harga yang efektif, dan terjamin. Cisco micro web server ini dapat digunakan untuk web hosting, mengatur suatu intranet workgroup perusahaan, dan mengupload router imej konfigurasi dan mendownload router update perangkat lunak. Berdasarkan pada arsitektur HyperText Transfer Protocol (HTTP), micro web server menawarkan suatu graphical user interface (GUI) Java dan data yang ada lebih besar dari 2 Mbps. Suatu disk drive sebesar 100 MB ZIP mengizinkan suatu distribusi informasi yang cepat dan otorisasi web. Sebagai tambahan, mendukung drive CD-ROM ganda dan hard drive dengan kapasitas sebesar 1.2 MB menetapkan solusi jaringan yang terdistribusi.

Ethernet Micro Web Server atau biasa disebut juga MWS V2.00 untuk Ethernet sangat mudah untuk mengontrol segalanya, dengan Ethernet diantara hal lainnya: diluar ataupun di dalam pencahayaan, alarm instalasi, webcam etcetera, dan etcetera. Micro web server akan dapat muncul di internet dengan menggunakan jenis ethernet jika memiliki ADSL- internet koneksi dan suatu router. Dengan kata lain, server akan terhubung dengan ethernet dimana maksudnya bahwa paling tidak dibutuhkan suatu komputer dengan kartu jaringan (networkcard) dan protokol TCP/IP. Angka acak dari micro web server dapat dihubungkan dengan jaringan. Server dapat digunakan dengan suatu web browser MSIE atau Netscape (sebagai contoh: http://192.168.255.100). PDA Micro Web Server merupakan micro web server yang dikembangkan dengan program Java yang mendukung eksekusinya dalam suatu lingkungan terbatas seperti profil pribadi J2ME. Komponen yang digunakan untuk kedua konten static (halaman HTML, imej, dan lain-lain) dan Java servlets yang dapat menurunkan konten dinamik. Server dgunakan dengan standar Java Servlet dan hanya membutuhkan

$60 \mathrm{~Kb}$. Sebagai tambahan, hal ini termasuk suatu pustaka yang dapat menyimpan dalam bentuk XML (aplikasi sinkronisasi terfokus). Bentuk ini dapat dikirimkan dengan model yang berbeda pada server pusat menggunakan perangkat 
sinkronisasi.

3) NCSA httpd ke Apache

Dua web server yang paling terkenal dari survei Netcraft adalah Apache dan NCSA (National Center for Supercomputing Application) httpd. Kedua server secara luas digunakan, walaupun menurut survei server Apache digunakan diatas dua kali situs seperti NCSA, dan pembagian pasar NCSA jatuh ketika Apache berkembang. Disini akan coba dijelaskan perbedaan antara NCSA httpd dan Apache sehingga pengguna kedua server dapat memutuskan jika bertemu kebutuhan lain yang lebih baik. Dengan kata lain disini dilihat direktif yang diubah antara NCSA dan Apache, yang mana dapat digunakan sebelumnya pada NCSA jika mereka memutuskan mengkonversi ke Apache.

NCSA versi 1.3 merupakan dasar perkembangan Apache. Pada awalnya, Apache merupakan suatu penggantian secara tibatiba untuk NCSA httpd, bagaimanapun keduanya yang dikembangkan saat ini memiliki beberapa perbedaan antara kedua server. Kemudian, kebanyakan kode Apache secara luas ditulis kembali, khususnya mengizinkan fungsionalitas menjadi diperluas dengan modules. Fitur ini menjelaskan bagaimana versi Apache saat ini dan NCSA httpd berbeda, apakah fitur Apache bertambah, dan ataupun dipersingkat. Hal ini diikuti dengan suatu daftar terperinci yang berubah antara NCSA dan Apache. Versi ini digunakan untuk memperbandingkan Apache dan NCSA http. Kemungkinan perbedaan yang paling utama antara Apache dan NCSA adalah bahwa Apache diperluas melalui suatu API program. Berarti bahwa fungsionalitas Apache dapat diperluas, melalui modules. Daftar fitur Apache memberikan konsentrasi pada fungsi yang ditetapkan oleh server dalam konfigurasi yang kurang, atau dengan penambahan modul yang didistribusikan sebagai bagian dari Apache. Bagaimanapun ada banyak penambahan modul yang dapat ditambahkan pada kinerja tugas khusus.

4) Micrososft IIS(Internet Information Service) Microsoft menciptakan IIS dalam Windows XP sehingga dapat digunakan langsung 
sebagai web server dalam infrastruktur komputer. Pendukung yang digunakandalam mengendalikan IIS di windows adalah web frontpage dan HTTP (sebagai pendukung standart dalam internet). IIS menggunakan host yaitu alamat IP (Internet Protocol). IIS menggunakan FTP (File Transfer Protocol) sebagai transfer data dan FTP restart (untuk download).

Beberapa program dukungan IIS

a. ASP (Active Service Page)

$b$. ASP yang memproses teks dan bekerja di server

c. XML (Extensible Markup Language)

d. PHP (Hypertext Preprocessor)

5) Microsoft PWS (Personal Web Server)

PWS merupakan ciptaan microsoft, PWS cocok dalam mempublikasikan halaman web perusahaan (departemen), dan halaman web sendiri. PWS juga memiliki kesamaan service dan teknologi seperti IIS, dengan publikasi web dengan web server volume tinggi.

Service dari PWS sendiri dalam hal pengembangan web,yaitu:

- Publikasi halaman web di Internet menggunakan HTTP

- Mendukung Microsoft ActifX control

- Transmisi dan menerima file menggunakan FTP.

Dan PWS memiliki program pendukung, yaitu :

1. ISAPI (Run Internet Server Page)

2. CGI (Common Gateway Interface)

Dalam menggunakan PWS, program komputer yang akan mengakses ke web server harus punya Transmission Control Protocol/Internet Protocol (TCP/IP) yang terdapat dalam windows 95, windows 98 dan windows NT.

\section{METODE PENELITIAN}

a) Analisa Permasalahan Vulnerability testing server sistem administrasi Web ini memang diperlukan. $\mathrm{Hal}$ ini dikarenakan server sistem administrasi tersebut memegang peranan yang sangat penting di Web. Vulnerability testing server ini dilakukan dengan 
tujuan untuk melalui cara download mengetahui dari internet) sendiri.

vulnerability yang ada.

Dari range IP address yang di-scanning, nantinya akan diketahui IP address yang mempunyai NMap dan yang tidak mempunyai NMap info. Setelah itu, dari NMap info yang ada, dapat diketahui IP address server. Selanjutnya, IP address tersebut akan discanning lagi dengan tools berbeda untuk melihat kelemahan yang dimiliki. Hasil dari scanning ini akan ditembus Laporan ini nantinya dapat memberikan evaluasi kepada pengelola jaringan komputer Web untuk lebih waspada lagi terhadap kelemahan yang ada.

b) Analisa Sistem

Penelitian ini, program aplikasi (tool) yang digunakan adalah program yang sesuai dengan langkah penetration testing. Tool yang digunakan ada yang didapatkan

c) Metodologi

Vulnerability Testing

Pada penelitian ini digunakan beberapa metodologi vulnerability testing . Adapun beberapa metodologi yang digunakan dalam penelitian ini adalah sebagai berikut:

a. Information Gathering. Information gathering merupakan salah satu dari langkah utama dalam melakukan vulnerability testing. Metodologi ini merupakan fase pertama dalam melakukan vulnerability testing dan dilakukan dengan menggunakan berbagai macam tools, scanners, online resource, mengirim http sederhana, dan lain-lain.

b.Vulnerability

Analysis. Vulnerability Analysis merupakan metode untuk 
mengidentifikasi

vulnerability dalam

suatu network.

Metodologi ini

menyediakan ringkasan

dari beberapa celah

atau flaw dari sistem

atau network.

c.

External

Vulnerability/Penetratio $\mathrm{n}$ Testing. External vulnerability testing dijalankan untuk mengetahui apakah external network tersebut aman atau tidak. Di dalam external.

d. vulnerability testing, hacking dilakukan dengan cara yang sama dengan seseorang yang melakukan attack tetapi sama sekali tidak membahayakan network.

e. Social Engineering.

Social Engineering adalah sebuah metode serangan yang digunakan oleh penyerang untuk mendapatkan informasi krusial dari sebuah perusahaan, biasanya dengan kontak langsung dengan target, secara verbal, maupun informasi mengenai target yang ditemukan dimanapun.

d) Alur Pengujian

Pada Gambar 1 dapat dilihat flowchart pengerjaan
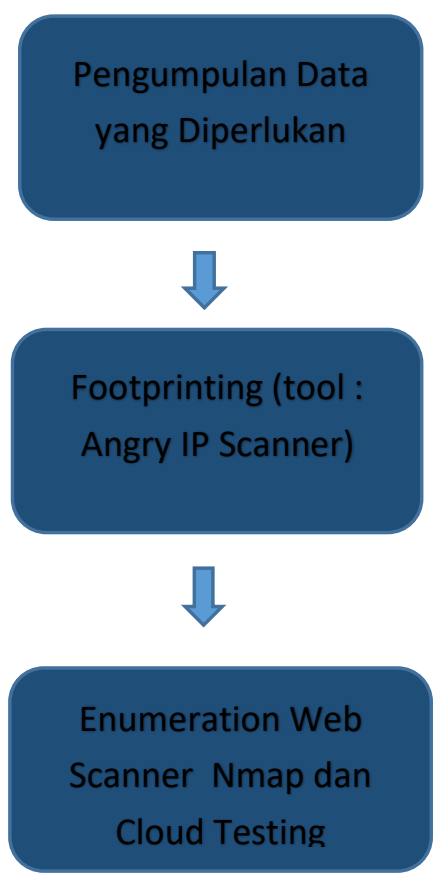

Cloud Testing

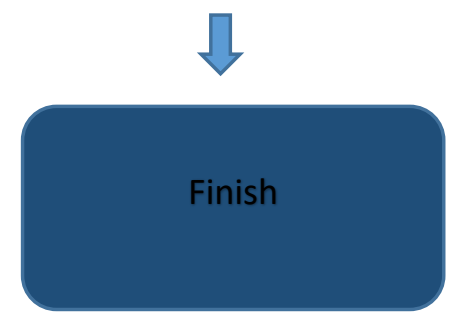


Pertama, user harus melakukan koneksi dengan WiFi dan melakukan autentikasi. Selanjutnya user dapat melakukan vulnerability testing untuk melakukan pengumpulan data.

\section{e) Penelitian Pengembangan Hosting Server}

Pada metode penelitian kami dengan menggunakan dua web server yang sama yaitu Apache dan Nginx, kedua web server ini ditujukan untuk wadah dari http yang cenderung kepada website dan email. Pengujian yang dilakukan adalah menguji performa kecepatan kedua web server untuk mengetahui kinerja masing-masing. Pengujian ini lebih kepada masalah cepat waktu yang digunakan untuk mengakses sebuah web.

Manakah web server yang lebih efektif dalam meng-handle setiap aktifitas yang dilakukan oleh user secara bersamaan. Kemudian dijabarkan bagaimana melakukan pengujian ini, setelah itu berlanjut pada hasil pengujian. Dan melakukan analisis kinerja web server Apache dan Nginx.

\section{- Kebutuhan Perangkat Keras dan Perangkat Lunak}

Analisis hosting server sistem operasi yang digunakan Linux, Ubuntu. Ubuntu termasuk sistem operasi open source dan free software dan sistem operasi server yang stabil.
Perangkat lunak hosting server yang akan diimplementasikan pada institusi perangkat lunak adalah web server, database server, DNS server, email server, file transfer. Server basis data yang akan dibangun pada hosting server infrastruktur institusi adalah server basis data MySQL server dan PostgreSQL server. Sebagai perangkat lunak untuk analisis pengembangan web server basis data, MySQL server dan PostgreSQL server memiliki kelebihan dan kekurangan masingmasing. Pada bagian lain penelitian pengembangan web server institusi, kedua perangkat lunak ini diperbandingkan untuk mengetahui perangkat lunak sistem database server mana yang lebih tangguh dan lebih baik. Selanjutnya perangkat lunak DNS server yang memiliki fungsi khusus yang digunakan sebagai master DNS server sehingga dalam proses konfigurasi dan penggunaannya lebih mudah. Dan mendukung penyimpanan data DNS dengan menggunakan basis data sehingga memudahkan dalam pengelolahan nama domain dan replikasi data DNS, spesifikasi tersebut antara lain dimiliki oleh Power DNS. Sedangkan untuk slave DNS, menggunakan Bind atau bisa disebut dengan penyimpanan kedua (secondary) yang mana data yang ada dalam Power DNS langsung tersingkronkan pada Bind sehingga ketika salah satu dari software DNS mati maka software yang lainnya yang akan membackupnya.

Email server menggunakan webmail roundcube dengan protokol 
IMAP dan Microsoft Outlook dengan protokol POP3. IMAP memungkinkan pengguna memilih pesan yang akan diambil, membuat folder di server, mencari pesan tertentu, maupun menghapus pesan yang ada dan terjadi komunikasi dua arah, sehingga terjadi sinkronisasi data. Sedangkan POP3 yang hanya memperbolehkan kita mengambil atau download semua pesan yang ada tanpa kecuali dan hanya bekerja dengan satu arah saja.

File transfer dibutuhkan software protokol SFTP dan FTP. SFTP dan FTP adalah suatu protokol dengan persamaan dapat tukar-menukar file dalam suatu network yang mensupport TCP/IP. Terdapat dua hal penting agar terjalinnya komunikasi data yaitu adanya sisi server dan client. Fungsi utama aplikasi ini adalah untuk mengakses mesin secara remote. Bentuk akses remote yang bisa diperoleh adalah akses pada mode teks maupun mode grafis/ $X$ apabila konfigurasinya mengizinkan.

- Rencana

Pelaksanaan Pengujian dan Analisis

Gambar 1 adalah diagram blok kerja alat, merupakan dinamika kerja sistem perangkat lunak pada hosting server, merupakan blok diagram pelaksanaan pengujian.

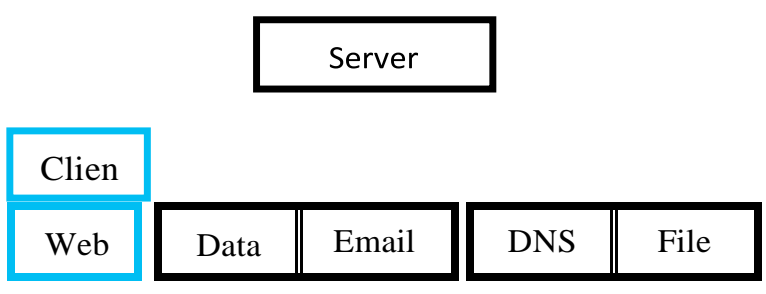

Gambar 1. Diagram Blok Hosting Server

diagram di atas percobaan web server yang diimplementasikan pada hosting server menggunakan program dengan software open source dan akan berjalan diatas sistem operasi Ubuntu. Cara kerja web server terhubung dengan server, email server, database server, DNS server, serta file transfer untuk upload dan download berkas-berkas yang berada didalam server. Web server yang berkerja sebagai backbone dari World Wide Web. Web server digunakan untuk berkomunikasi dengan client-nya (web browser). Pelaksanaan pengujian dan menganalisis untuk pengembangan hosting server institusi menggunakan perangkat keras dan perangkat lunak dengan spesifikasi perangkat keras server merupakan komponen server komputer berfungsi operasional, penyimpan, dan proses sistem dengan spesifikasi seperti pada Tabel 1. Sedangkan spesifikasi perangkat lunak hosting server, dibutuhkan software seperti Sistem Operasi Linux Ubuntu version 14 dengan aplikasi didalamnya seperti : 
1) Web Server: Apache, Nginx, dan PHP5

2) Database Server : Mysql dan PostgreSQL

3) DNS Server : Power DNS dan Bind

4) Email Server : Postfix, Roundcube, dan MS

Outlook

5) File Transfer : SFTP dan FTP

\section{HASIL DAN PEMBAHASAN}

\section{A. Foot Printing}

a.Physical(Environmental)

Security Setiap vulnerability diberikan solusi sebagai berikut :

- Pintu ruang server yang selalu terbuka. Pintu di ruang server harus ditutup dengan tujuan agar hanya orang yang berkepentingan yang dapat keluar masuk ruang server.

- Terdapat barang-barang selain server sistem administrasi Website. Barangbarang yang tidak berhubungan dengan server sistem administrasi diletakkan di tempat sesuai dengan fungsinya.

- Air conditioner yang mengalami kebocoran. Dilakukan maintenance terhadap Air conditioner sesuai dengan periode tertentu.Hanya terdapat smoke detector, namun tidak ada alat pemadam api. Seharusnya di sebuah ruangan server diberi fasilitas pemadam api, seperti water sprinkler, atau penyemprot karbondioksida supaya api dapat sesegera mungkin terdeteksi dan dapat dipadamkan secara cepat sehingga server tidak mengalami kerusakan.

b. Angry Ip Scanner Setelah melakukan autentikasi langsung ke website dengan menggunakan IP static dan mengetahui topologi network public domain, langkah selanjutnya yang dilakukan yaitu melakukan scan IP address yang memiliki range dengan menggunakan Angry ip Scanner untuk mengetahui detail siapa saja yang terkoneksi dalam jaringan sesuai dengan topologi network Website.

B. Vulnerability Testing dengan Nmap dan Cloud Testing

a.PortChecking(Nmap) Kelemahankelemahan yang telah ditemukan pada langkah sebelumnya, yaitu enumeration and scanning networks, akan digunakan untuk masuk ke dalam server dan dibahas kelemahan-kelemahan yang ditemukan. Kelamahan-kelemahan tersebut ditemukan karena adanya port-port yang terbuka.

b. Topologi Jaringan Kemudian scan dilanjutkan untuk mengetahui mapping dari jaringan dan server.

c. Host Status dan Operating System(Nmap) Pengujian juga dilakukan untuk mengetahui Host Status dan Sistem Operasi yang digunakan.

d. Pengujian Cloud Pengujian akhir dari 
server

Peneliti menggunakan fasiltas pengujian web yang sudah disediakan oleh beberapa web ternama yang bersifat cloud computing. Dari hasil pengujian didapatkan hasil penilaian yang baik pada Web Server.

- Pengujian pada Web Inspector Pada pengujian web inspector tidak ditemukan masalah yang menimbulkan hal yang berbahaya di Server. Seperti halnya malware, phising, worm, trojan, blacklist checking, dan lain sebagainya yang berkaitan dengan semua hal yang dapat mengganggu pada keamanan sebuah server.

- Pengujian Grade Pada Qualis SSL Lab Pada pengujian peringkat keamanan yang dimiliki Server didapatkan nilai A-. Minus ini dikarenakan Serverbelum mempunyai Forward Secrecy pada beberapa browser utama.

\section{Data Hasil pengujian Hosting Server}

Dari hasil pengujian yang telah dilakukan sebelumnya antara web server Apache dan web server Nginx yang diuji menggunakan ubuntu server, dengan waktu pengujian selama 60 second dan 10 request koneksi secara bersamaan dan pelaksanaan pengujian dilakukan 3 kali percobaan untuk setiap halamannya, maka didapatkan hasil.Hasil didapatkan menggunakan pembulatan angka, jika di belakang koma muncul angka 1-5 maka dijadikan 0 , sedang angka 69 dijadikan 1.

Hasil pengujian halaman index :

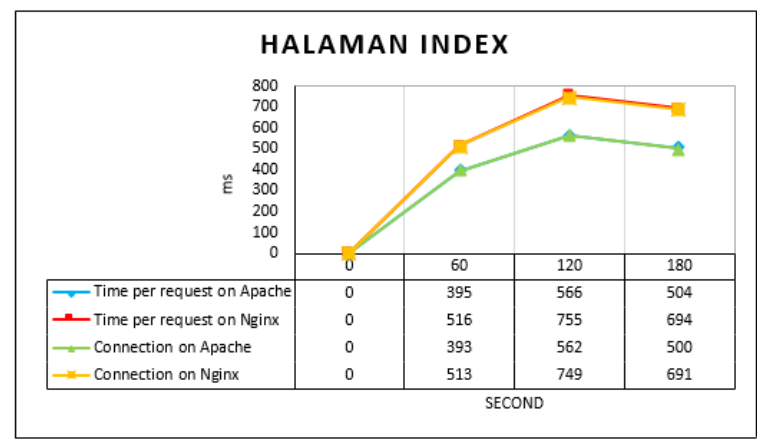

Pengujian Halaman Index

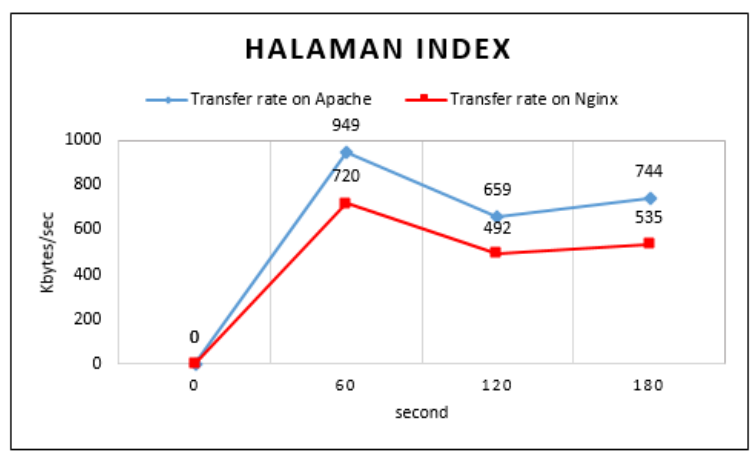

Grafik Pengujian Halaman Index

Pada Gambar menjelaskan grafik dari hasil pengujian yang dilakukan pada halaman index untuk setiap variabelnya dari 60 second pertama sampe 60 second ketiga.

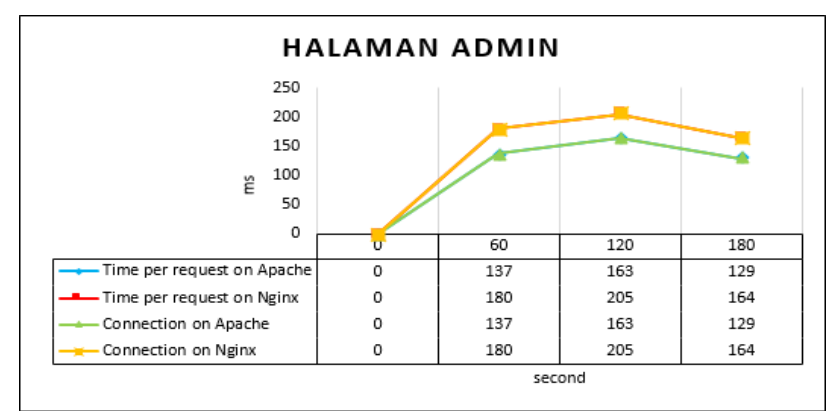


Pada Gambar grafik yang dihasilkan dari pengujian halaman admin yang ilakukan sebanyak 1 kali percobaan

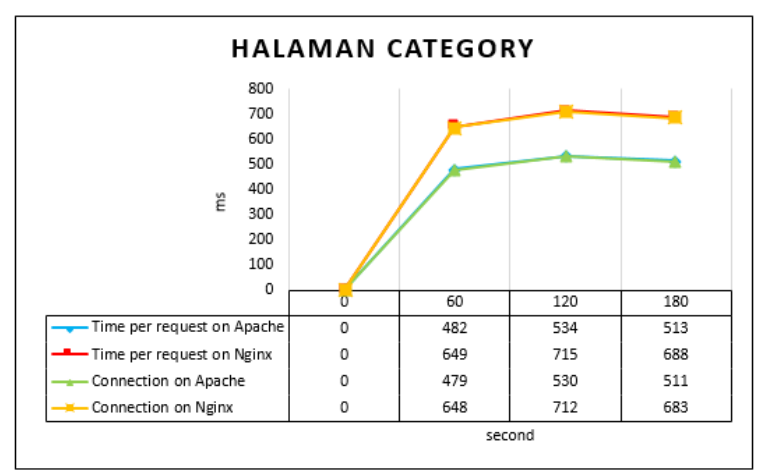

Grafik yang didapatkan dari halaman category pada pengujian web server pada variable transfer rate. Hasil pengujian halaman authentication.

\begin{tabular}{|c|c|c|c|c|}
\hline No & Variable & $\begin{array}{c}\text { Percobaan } \\
1\end{array}$ & $\begin{array}{c}\text { Percobaan } \\
2\end{array}$ & $\begin{array}{c}\text { Percobaan } \\
3\end{array}$ \\
\hline 1 & $\begin{array}{l}\text { Time per } \\
\text { Request on } \\
\text { Apache }\end{array}$ & $\begin{array}{c}482.511= \\
482(\mathrm{~ms})\end{array}$ & $\begin{array}{l}533.910= \\
534(\mathrm{~ms})\end{array}$ & $\begin{array}{c}512.826= \\
513(\mathrm{~ms})\end{array}$ \\
\hline 2 & $\begin{array}{l}\text { Time per } \\
\text { Request on } \\
\text { Nginx }\end{array}$ & $\begin{array}{c}649.507= \\
649(\mathrm{~ms})\end{array}$ & $\begin{array}{c}715.515= \\
715(\mathrm{~ms})\end{array}$ & $\begin{array}{l}687.647= \\
688(\mathrm{~ms})\end{array}$ \\
\hline 3 & $\begin{array}{l}\text { Connection } \\
\text { Times on } \\
\text { Apache }\end{array}$ & 479 (ms) & $530(\mathrm{~ms})$ & 511 (ms) \\
\hline 4 & $\begin{array}{l}\text { Connection } \\
\text { Times on } \\
\text { Nginx }\end{array}$ & $648(\mathrm{~ms})$ & $712(\mathrm{~ms})$ & $\begin{array}{c}683 \\
(m s)\end{array}$ \\
\hline 5 & $\begin{array}{l}\text { Transfer Rate } \\
\text { on Apache }\end{array}$ & $\begin{array}{c}773.83 \\
=774 \\
\text { Kbyetes } / s \text { ) }\end{array}$ & $\begin{array}{c}699.34=699 \\
\text { (Kbyetes } / s)\end{array}$ & $\begin{array}{c}729.95= \\
730 \\
\text { (Kbyetes } / s)\end{array}$ \\
\hline 6 & $\begin{array}{l}\text { Transfer Rate } \\
\text { on Nginx }\end{array}$ & $\begin{array}{c}573.29 \\
=573 \\
(\text { Kbyetes } / s)\end{array}$ & $\begin{array}{c}520.47=520 \\
(\text { Kbyetes } / s)\end{array}$ & $\begin{array}{c}543.36= \\
543 \\
\text { (Kbyetes } / s)\end{array}$ \\
\hline
\end{tabular}

Grafik di atas menjelaskan nilai dari hasil pengujian authentication yang didapatkan dari pengujian transfer rate.

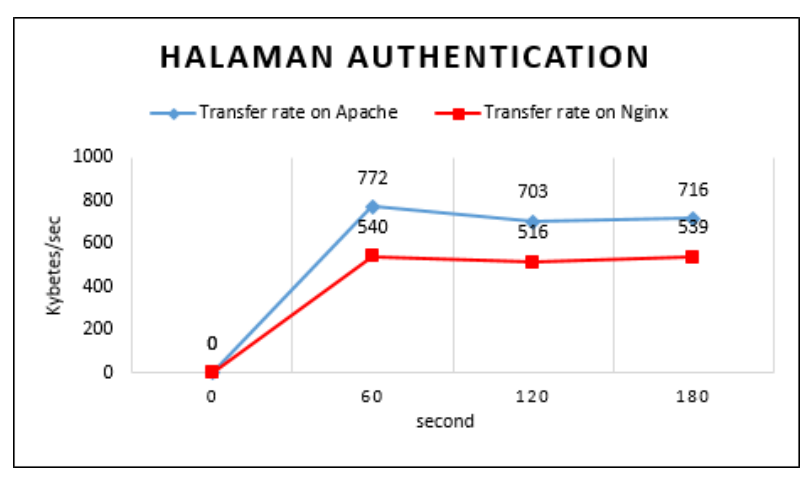

\section{KESIMPULAN}

Berdasarkan dari semua yang telah dilakukan selama pengerjaan penelitian, dapat disimpulkan beberapa hal, antara lain:

a. Kelemahan physical security yang ditemukan tidak direkomendasikan untuk sebuah ruangan server karena rentan terhadap orang luar yang masuk ke dalam ruang server dan mengambil perangkat keras yang ada, serta

b. Rentan terhadap rentan terhadap disaster seperti kebakaran dan terkena air.

c. Terbukanya beberapa port yang tidak sesuai dengan fungsinya. Hal ini dapat menyebabkan adanya celah yang dapat dimanfatkan untuk diserang. $d$. Pada Pengujian Cloud Web dikatagorikan dalam kondisi baik.

Analisa kinerja dari kedua web server dengan parameter transfer rate, time per request, dan connection time sebagai indikator pengukuran untuk pengujian kinerja dari kedua web server. Dan metode pengujian menggunakan proses benchmark didapatkan hasil bahwa transfer rate pada web server Apache adalah 949 Kbytes/sec, 354 Kbytes/sec, $774 \mathrm{Kbytes} / \mathrm{sec}, 772$ Kbytes/sec, $660 \mathrm{Kbytes} / \mathrm{sec}$ dan web server Nginx $=720 \quad$ Kbytes $/ \mathrm{sec}, 268$ 
Kbytes/sec, 573 Kbytes/sec, $540 \quad$ Kbytes/sec, 510 Kbytes/sec. Time per request pada web server Apache $=395$ $\mathrm{ms}, 137 \mathrm{~ms}, 482 \mathrm{~ms}, 474 \mathrm{~ms}$, 566 ms. Dan pada web server Nginx $=516 \mathrm{~ms}, 180 \mathrm{~ms}, 649$ $\mathrm{ms}, 676 \mathrm{~ms}, 728 \mathrm{~ms}$. connection time pada web server Apache $=$ $393 \mathrm{~ms}, 137 \mathrm{~ms}, 479 \mathrm{~ms}, 472$ $\mathrm{ms}, 564 \mathrm{~ms}$ dan web server Nginx $=513 \mathrm{~ms}, 180 \mathrm{~ms}, 648$ $\mathrm{ms}, 672 \mathrm{~ms}, 725 \mathrm{~ms}$.

Kesimpulan analisis dari hasil pengujian tersebut ditemukan web server Apache memiliki kinerja lebih baik dari pada web server Nginx, dimana kemungkinan pengguna web server Apache belum mengetahui. Hal tersebut bahwa web server Apache memiliki kecepatan transfer rate, time per request dan connection time lebih cepat dibandingkan dengan Nginx, dimana dengan nilai transfer rata-rata dari Apache 701 Kbytes/sec sedangkan Nginx 522 Kbytes.

\section{REFERENSI}

- http://jurnal.stmik-amikriau.ac.id/index.php/satin/article/vie w/298

- http://journal.uinjkt.ac.id/index.php /sisteminformasi/article/view/291

- https://www.researchgate.net/profil e/Abdul Aziz45/publication/329836 851 Analisis Web Server untuk Pe ngembangan Hosting Server Institu si Pembandingan Kinerja Web Ser ver Apache dengan Nginx/links/5d 6fc24092851cacdb204cc4/AnalisisWeb-Server-untuk-PengembanganHosting-Server-InstitusiPembandingan-Kinerja-Web-ServerApache-dengan-Nginx.pdf 
